\title{
Screening of cancer cervix: Pap smear in rural India
}

\author{
Parimala A., Nidhi Sharma*, Jayashree K. Srinivasan
}

Department of Obstetrics and Gynaecology, Saveetha Medical College, Saveetha University, Chennai, India

Received: 07 June 2016

Accepted: 20 June 2016

\section{*Correspondence:}

Dr. Nidhi Sharma,

E-mail: drbonuramkumar@yahoo.co.in

Copyright: (C) the author(s), publisher and licensee Medip Academy. This is an open-access article distributed under the terms of the Creative Commons Attribution Non-Commercial License, which permits unrestricted non-commercial use, distribution, and reproduction in any medium, provided the original work is properly cited.

\begin{abstract}
Background: The incidence of cervical premalignant lesions in rural India is likely to be high due to presence of several risk factors like early marriage, early coitarche and multiparity. Hence prospective cross sectional study was conducted to find the incidence of pre-invasive state and cancer of cervix in women between the age group 30 and 60 years, visiting Thirumazhisai health centre by Pap's smear method.

Methods: Cervical mucosa is scraped, using Ayre spatula a $360^{\circ}$ turn is made at the transition zone and smeared on a slide and papanicolaou stain is applied and the slide is examined under microscope. If Pap's smear confirms low/high grade lesion, biospy is done to confirm the finding. The result is analysed for pre-invasive state.

Results: Out of the cases (107) examined with in the study period, 36.45\% were normal. Out of the rest $47.05 \%$ had an inflammatory smear, $14.7 \%$ had active bacterial infection, $17.65 \%$ had active candida infection and $5.88 \%$ had high-grade intraepithelial lesion (CIN 3).

Conclusions: The incidence of high-grade lesion for cervical cancer is high among the rural population and they are susceptible to develop the cancer. Regular screening for cancer of uterine cervix is of need among people of lower socio economic status. Awareness should be created on cervical cancer and its complications.
\end{abstract}

Keywords: Cervical cancer screening, Cytology, Rural community, Pap smear

\section{INTRODUCTION}

Cervical cancer is one of the most common cancers among women worldwide. ${ }^{1}$ A long premalignant course makes this cancer amenable for screening by Pap smear. ${ }^{2}$ Cancer that develops in the ectocervix is called squamous cell carcinoma, and around $80-90 \%$ of cervical cancer cases (more than $90 \%$ in India) are of this type. Cancer that develops in the endocervix is called adenocarcinoma. In addition, a small percentage of cervical cancer cases are mixed versions of the above two, and are called adenosquamous carcinomas or mixed carcinomas.

Cervical cancer is the third largest cause of cancer mortality in India after cancers of the mouth and oropharynx, and oesophagus, accounting for nearly $10 \%$ of all cancer related deaths in the country. Among women, it is the leading cause of cancer mortality, accounting for $26 \%$ of all cancer deaths. According to International agency for research in cancer estimates, mortality from cervical cancer is expected to witness a $79 \%$ increase from 74,118 deaths in 2002 to 132,745 deaths by 2025 .

There are several studies in recent 5 years reported on evaluation of various screening methods including VIA and cytology. ${ }^{3-6}$ As there was no large scale cervical cancer screening study in this part of rural Tamil Nadu, a study was initiated in the year 2013 with an aim to evaluate the demonstration of cytology in a rural setting. Thus the present study reports cytology screening results of pap tests for detection of cervicitis and HSIL in asymptomatic women in rural health center.

The aims was to find the incidence of pre-invasive state (cervical intraepithelial neoplasia I and II) and cancer of 
cervix in women between the age group 30 and 60 years, visiting Thirumazhisai urban health centre by Pap's smear method.

\section{METHODS}

The selected study area of a Tehsil of Thirumazhisai District (Tamil Nadu), India had a population of 1.5 lacs covered by community health center (CHC), along with the attached four primary health centers (PHC) with their 34 sub-centers. Eligible women between 30 and 60 years were enumerated by a base-line survey. All the eligible target group women were invited for screening and no further selection of women was done. Most of the screening centers were established at PHC and sub centers or at a convenient place. Exclusion criterion was women who had undergone a total hysterectomy and previously diagnosed with cancer or pre-cancer. Women who were menstruating at the time of the study visit were excluded temporarily. Pregnant women were eligible to participate in study 12 weeks after the end of pregnancy. The duration of the study was 1 year from November 2013 to October 2014.

The informed consent is obtained from all the (107) patient and all the following procedures are done under sterile conditions. Cervical mucosa is scraped, using Ayre spatula a $360^{\circ}$ turn is made at the transition zone and smeared on a slide and papanicolaou stain is applied and the slide is examined under microscope. If Pap's smear confirms low/high grade lesion, biospy is done to confirm the finding. The result is analysed for pre-invasive state (cervical intraepithelial neoplasia I and II) and cancerous of cervix. The treatment of precancerous lesions was done as per IARC guidelines. ${ }^{7}$

\section{RESULTS}

Out of the cases examined with in the study period, $36.84 \%$ were normal. Out of the rest $47.05 \%$ had an inflammatory smear, $14.7 \%$ had active bacterial infection, $17.65 \%$ had active candida infection and $5.88 \%$ had high-grade intraepithelial lesion (CIN 3) (Figure 1).

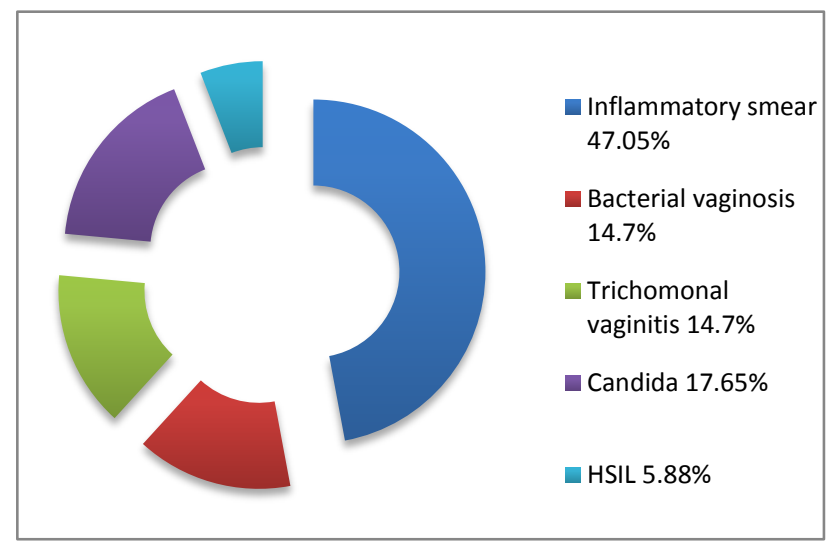

Figure 1: Cervical cytology with Pap smear.

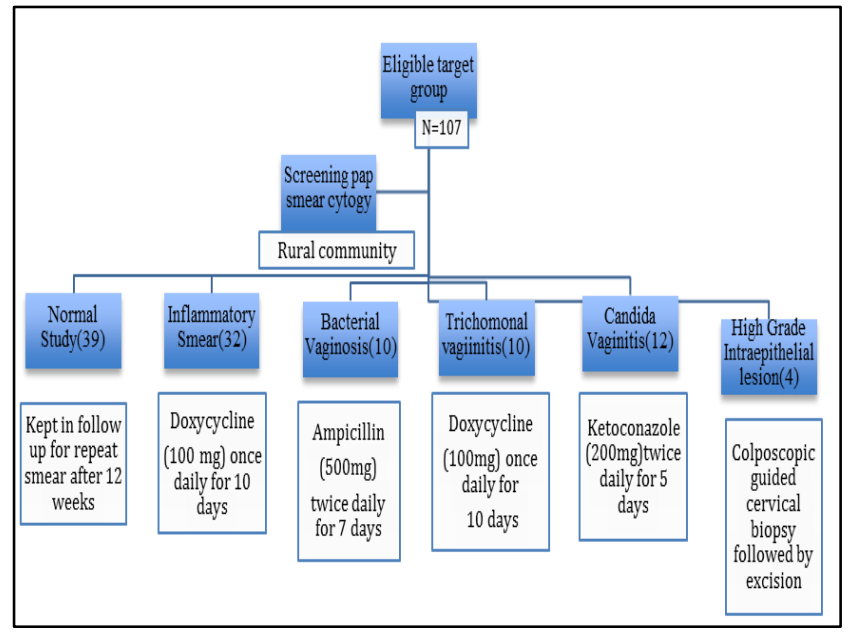

Figure 2: Papanicolau staining results.

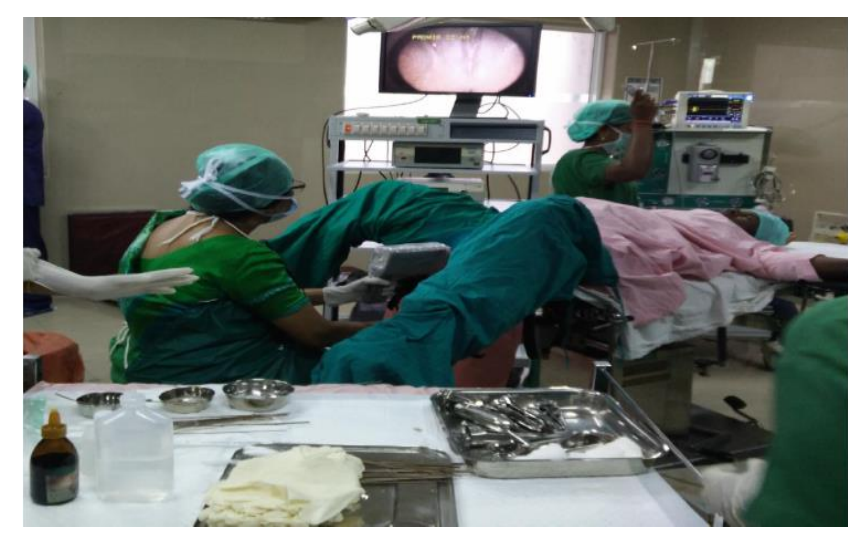

Figure 3: Colposcopic guided cervical biopsy in a case of HSIL.

\section{DISCUSSION}

Pap screening has been demonstrated as a feasible primary screening test for detecting high grade CIN and to referral for colposcopy and HPV testing when required. In other studies sensitivity and specificity of detecting the CIN III+lesions were 87.5 and $98.8 \%$ for Pap, $50.0 \%$ and $96.7 \%$ for VIA and $50.0 \%$ and $95.7 \%$ for VILI respectively. In India, Tamil Nadu government has already initiated district level VIA and VILI screening on a pilot basis to demonstrate that VIA/VILI is an appropriate cost-effective screening tool in low resource settings. This was based on randomized controlled trials depicting the cost effectiveness of VIA in cervical cancer screening. ${ }^{8}$ The pilot program was demonstrated to be conducive for scaling up across the state. ${ }^{9}$ Although, taking a Pap smear of all the eligible women in rural Tamil Nadu can detect numerouscases, which are missed by VIA, and VILI. Some researchers have raised serious doubts of visual inspection with acetic acid to screen women $\geq 40$ years of age for carcinoma cervix. ${ }^{10}$

Studies have depicted a superior efficacy of Pap smear and histology in combination with colposcopy in screening of cervical lesions. ${ }^{11}$ In rural Delhi, India, the 
role of cervical cytology and colposcopy has been emphasized. ${ }^{12}$ In those studies where VIA and VILI have been indicated for mass screening, positive predictive values were highest for Pap and lower for VIA and VILI respectively. $^{3}$

The study found $5.26 \%$ incidence of HSIL with Pap smear in rural Tamil Nadu, India. The benefit from a universal Pap Screen is likely to be better compared to VIA and VILI. Several studies have depicted a superior efficacy of Pap smear and cervical cytology in community screening of cancer cervix. ${ }^{13}$

Cervical cancer screening needs to be reinforced in rural population by flip charts, radio talks, community group talks, personal communication, handouts and posters. Paramedical workers need to be trained in cervical cytology through skill development workshops to screen the community. Thus our study concludes that although VIA and VILI is cost effective, the role of cervical cell study with Pap smear in screening of cancer cervix cannot be over ruled.

\section{CONCLUSION}

The study concluded that, the incidence of high grade lesion for cervical cancer is high among the rural population and are susceptible to develop the cancer. Regular screening for cancer of uterine cervix is of need among people of lower socio economic status and awareness should be created on cervical cancer and its complications.

Funding: No funding sources

Conflict of interest: None declared

Ethical approval: The study was approved by the Institutional Ethics Committee

\section{REFERENCES}

1. Ferlay J, Bray F, Pisani P, Parkin DM. Cancer incidence, mortality and prevalence worldwide. Lyon, France:IARC press;2004 (Version 1.0. IARC Cancer Base No. 5). GLOBOCAN;2002.

2. Papanicolau GN, Traut HF. Diagnosis of uterine cancer by the vaginal smear. The Anatomical Record. 1943;86(4):591-2.

3. Satyanarayana L, Asthana S, Bhambani S, Sodhani P, Gupta S. A comparative study of cervical cancer screening methods in a rural community setting of north India. Indian J Cancer. 2014;51:124-8.
4. Deodhar K, Sankaranarayanan R, Jayant K, Jeronimo $\mathrm{J}$, Thorat R, Hingmire $\mathrm{S}$, et al. Accuracy of concurrent visual and cytology screening in detecting cervical cancer precursors in rural India. Int $\mathbf{J}$ Cancer. 2012;131:954-62.

5. Li R, Zhou Q, Li M, Tong SM, He M, Qiu H, et al. Evaluation of visual inspection as the primary screening method in a four-year cervical (pre-) cancer screening program in rural China. Trop Doct. 2013;43:96-9.

6. Longatto FA, Naud P, Derchain SF, Roteli MC, Tatti S, Hammes LS, et al. Performance characteristics of Pap test, VIA, VILI, HR-HPV testing, cervicography, and colposcopy in diagnosis of significant cervical pathology. Virchows Arch. 2012;460:577-85.

7. Sellors JW, Sankaranarayanan R. Colposcopy and treatment of cervical intraepithelial neoplasia: A beginners' manual. Lyon, France: IARC Press,WHO;2003.

8. Sankaranarayanan R, Esmy PO, Rajkumar R, Muwonge R, Swaminathan R, Shanthakumari S, et al. Effect of visual screening on cervical cancer incidence and mortality in Tamil Nadu, India: A cluster-randomised trial. Lancet. 2007;370:398-406.

9. Tamil Nadu Health Systems Project. Available from: http://www.tnhsp.org/screening-cervical-cancer-andbreast-cancer.Accessed on 28 February 2016.

10. Dasgupta $S$, Bhattacharya $S$. Is visual inspection with acetic acid better than cervical cytology to screen women $\geq 40$ years of age for carcinoma cervix? A cross-sectional study on proportion of screenpositive women (by VIA and cervical cytology) having CIN II/III lesion on cervical biopsy: difference between two age groups and among screening methods. Arch Gynecol Obstet. 2012;285:1731-6.

11. Krishnegowda S, Ms V. Efficacy of colposcopy technique with Pap smear and histology in screening of cervical lesions. Int Reprod Contracept Obstet Gynecol. 2014;3(3):696-702.

12. Bhatla N, Gulati A, Mathur SR, Rani S, Anand K, Muwonge R, et al. Evaluation of cervical screening in rural North India. Int $\mathrm{J}$ Gynaecol Obstet. 2009;105:145-9.

13. New approaches to cervical cancer screening: developing aneffective programme for the world. Presented at the 10th European cancerconference, September 15, 1999. Available at www.medscape.com/ medscape/cno/1999.ECCO/ Story.cfm?story_id=783. Accessed on 8 March 2016.

Cite this article as: Parimala A, Sharma N, Srinivasan JK. Screening of cancer cervix: Pap smear in rural India. Int J Reprod Contracept Obstet Gynecol 2016;5:2113-5. 